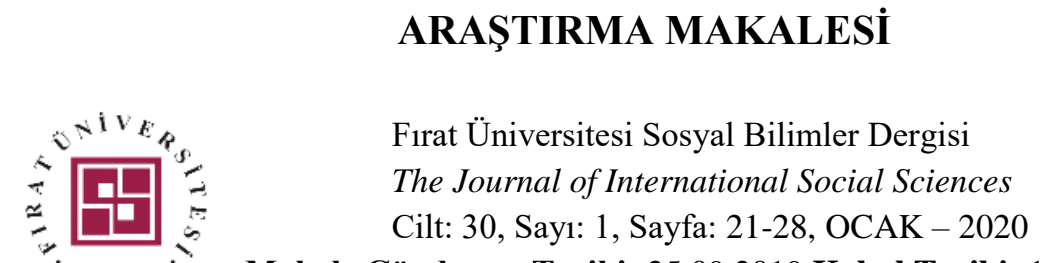

Makale Gönderme Tarihi: 25.09.2019 Kabul Tarihi: 11.12.2019

\title{
“AŞK MÜLKÜNÜN SULTANI” MOLLA NEFES VE LIRİK YARATICILIĞI
}

\author{
“The Sultan of Love Property” Molla Nephes and His Lyric Creativity
}

\section{Aynur SEFERLí \\ ÖZ}

\begin{abstract}
Molla Nefes'in Türkmenlerin “Teke”, "Yazı”, "Toktamış” boylarından olduğuna dair bilgiler vardır. İlk eğitimini babasından ve zamanının meşhur bir pedagog bilgini olan Molla Muhammed Saleh'ten aldığı tahmin edilmektedir. Kendini halkının, milletinin çocuklarına adamış şairin ismine ilave edilen "molla" kelimesinin de nedeni budur. Şair, Türkmenler arasında "Aşk mülkünün sultanı” olarak bilinir. Eserlerinin çoğu, insanın doğal görünümünden bahseder. Şiirlerindeki ses, müzik, üslup, anlam ve söz sanatları; ritim ve kafiye yapısı bakımından orijinaldir. Sanatçının farklılıklar ve yenilikler arayışında bulunması, şiirsel hassasiyetinin ve gücünün göstergisidir. Şairin yaratıcılığının şaheserlerinden olan «Ben bu mekâna gelmişem» poemidir. Bu eserde sevginin en yüksek şiirsel seviyede olduğunu görürüz. İslam dininin yücelerini ve erenlerini bile şair poemine dahil etmiştir. Allah'ın bile âşık olduğu kız aslında Molla Nefes'in bir zamanlar sevdiği, ama hiç bir zaman kavuşamadığı sevgilisi Durduhal'mış. Kim görürse bu kızı sevdiğini unuturmuş. Yer yüzündeki kargaşayı görüp de kimi gönderdiyse sonuç alamadığını görünce Allah, kendisi dünyaya iner. Kızı görünce Allah bile kendinden geçer. Şairin birçok şiirinin zamanla Feraki, Kemine, Talibi, Andelip' gibi şairlere ait olduğu sanılmıştır.
\end{abstract} lirizmi

Anahtar Kelimeler: “aşk mülkünün sultanı”, şiirsel seviye, şiirsel duyarlılık, ilahi aşk, Molla Nefes

\begin{abstract}
It is estimated that Molla Nephes was from the "teke", "writing", "tokhtamış" tribes of the Turkmens. It is estimated that she received her first education from her father and Molla Muhammed Saleh, a famous pedagogue scholar of her time. Air molla bu is the reason for the word. This poet is known as s the sultan of love property arasinda among the Turkmens. Most of his works speak about the natural appearance of the people. The sound, music, style, meaning and rhetorical arts in his poems are original in terms of rhythm and rhyme structure. the search for innovations, poetic sensitivity and strength of the poem. That girl was actually her lover Durduhalmla, whom Mulla Breath once loved but could never prosecute. Who sees this girl loves to see the turmoil on the face of the sender who can not get the result of seeing who can not get God itself goes down to the world.Girl passes by itself.Firaki poetry a lot of time Feraki, Kemine, Talib, Andelipe even belonged.
\end{abstract} lyricism

Keywords: "sultan of love property “, poetic level, poetic sensitivity, divine love, Molla Nephes

\section{GíRIŞ}

"Nurmuhammed Andelip, D. Azadi, M. Feraqi, M. Kemine, Molla Nefes gibi yüzlerce âlimlerimiz, müdriklerimiz, şairlerimiz, sanat üstatlarımız sönmez iz koydular, bilim ve sanat dünyasında büyük üne sahip oldular. Kalbimizde, hafızamızda "aşk mülkünün sultanı" hükmünde bâki yer tutan Molla Nefes beşer duygularının gerçek terennümcüsüdür, insan kalbine, insan

\footnotetext{
* Doktora öğrencisi (Bakı Devlet Universitesi), Öğretim görevlisi (Azerbaycan Diller Universitesi), AZERBAYCAN, BAKI; e-posta: seferli_1988@bk.ru , ORCID: https://orcid.org/0000-0002-0110-4659
} 
yüreğine ruhsal merhem veren şairdir” (Türkmenistan Devlet Başkanı Gurbanguli Berdimuhemmedov).

Türkmen şiirinin önemli isimlerinden olan M. Nefes, Azerbaycan edebiyatında derinden incelenmemiş edebî şahsiyyetlerdendir. Onun edebî mirasının araştırılması, XIX. yüzyıl Türkmen edebiyatının değerini ortaya çıkarmak açısından önemli olacaktır.

M. Nefes'in yaratıcılığının incelenmesi alanındaki boşluğu Azerbaycan'da profesör Ramiz Asker, Türkiye'de ise Gökcegöz oğlu (2015), Gökçimen (2010) ve Kaya (2010) tarafından yazılan makaleler doldurur. Hatta "Kardeş kalemler" \ dergisinin 39. sayısı tamamen şaire adanmıştır.

\section{Molla Nefes'in hayatı}

Türkmenistan Cumhurbaşkanı Gurbangulı Berdimuhammedov'un sözlerine göre, kalbimizde, hatıramızda "aşk mülkünün sultanı" hükmü ile yer tutan Molla Nefes, beşerî duyguların hakiki terennümcüsüdür, insanın kalbine ve ruhuna ilaç olan bir şairdir" diye söz ettiği edip, XIX. asırda yaşamış değerli isimlerdendir ki, onun hayat ve yaratıcılığının incelenmesi, Türkmen edebiyatındaki yeri ve önemi açısından önemlidir. Hayatı hakkında çok az bilgiye sahip olduğumuz Molla Nefes'in, 1810'da Merv'de (Mari’de), “Teke" Türkmenlerinin, bir kaynağa göre, "Yazı", başka bir malumata göre ise "Toktamış" tayfasına mensub Kadirverdi adlı bir saracın ailesinde doğduğuna inanılıyor. Onun Ağacık Bahşı, Ödekverdi, Hakverdi ve Molla Nefes adında dört oğlu vardı. Uzmanlara göre, "Molla Nefes" şairin takma adıdır. Onun gerçek adı Tanrıverdi'dir. Şairin torununa göre, Hive'de okurken öğretmenleri ona bu isimle hitap etmişlerdir (Nefes 2010:4). Hudaverdi Berkeliyev'e göre Ödekverdi'nin Molla Eğerçi adlı bir oğlu olmuştur ve sonraları ona babaları Kadirverdi ismini vermişlerdir. Hakverdi'nin ise Meşreb isimli oğlu olmuştur. Molla Nefes'in ise Mehemmed Rahim (bazı kaynaklarda Molla Rahim diye geçiyor. Bu sebeple her iki isimle yazdık) ve Molla Resul adlı iki oğlu olur. Molla Resul'un da babasının ismini verdiği Molla Nefes ve Amancan adlı iki oğlu olur. Molla Nefes hakkındaki bu ön veriler, Hocalı Molla'nın Samoyloviç'e gönderdiği malumattır ki, El Yazması Enstitüsü'nün 2121 klasöründeki muhafaza edilmektedir. Bu bilgi, aynı zamanda halktan toplanan bilgilerle de örtüşmektedir. Bu derlenmiş veriler Yazmurad Nuriyev'in Mari vilayeti Makrub civarında yaşayan Hudaverdi Berkeliyev'den aldığı bilgilerdir. Nazar Qurreyev'in Mari dolaylarında Molla Nefes'in torununun evladından aldığ 1 bilgilerdir. Molla Nefes'in torununun evladından aldığı bilgilerde de Molla Nefes'in iki oğlu olduğu yer almaktadır (Aşırov 2010:6-7).

İlk eğitimini babasından ve zamanının tanınmış bir pedagog bilgini olan Molla Muhammed Saleh'ten aldığı tahmin edilmektedir. Molla Nefes çoçukluktan zekâsı ve anlayışı nedeniyle kardeşleri ve akranlarından farklıydı. Bu nedenle babası Kadirverdi şairin gelecekteki eğitimine çok dikkat etti ve köy okulundaki ders kitaplarından başka kendisi de bilhassa ilgilenmiş, Molla Nefes'in dünya görüşünün oluşumunu büyük ölçüde etkilemiştir. Daha sonra eğitimine, zamanının medreselerinden biri olan Buhara medresesinde devam etti. Bu sebeple şiirlerindeki Özbekçe sözler, şairin orada okuduğu yılların hatırası olarak karşımıza çıkıyor. Medresede okuduktan sonra Merv'e geri dönen şair, kendisini halkın çocuklarına adamış, onları okutmuş, yaşadığı sosyal çevrenin dinî işleriyle meşgul olmuştur. Şairin adına eklenmiş olan "Molla" kelimesinin nedeni de budur. Türkmenler arasında "Aşk mülkünün sultanı " olarak bilinen şairin eserlerinin büyük bir çoğunluğu, insanın doğal görünümünden bahseder (http: //www yagmurdergisi.com.tr / konu / 19-asır-turkmen şairi-mollanepes). Molla Nefes Çağatay, Arap ve Fars dillerini öğrenmenin yanı sıra Kur'an, hukuk, dil, tarih, coğrafya ve teoloji gibi diğer ilimlere sahip olmuştur. Çalışma yılları boyunca, Fuzuli, Nesimi, Nevayi, Yunus Emre, Nizami, Sadi, Hafız, Cami, Hoca Ahmed Yesevi, Türkmen şairlerinin şiir ve sözlü halk edebiyatı öyküleriyle birlikte Şark poetik şiir ve hikâyelerini mükemmel bir şekilde öğrenmiş ve ilk eserlerini de burada yazmaya başlamıştır.

Şairin neslinin erkek kısmının, 1940'lardan sonra II. Dünya Savaşı döneminde oluşmuş açlığın etkisinden dolayı meydana gelen karın yatalağı denilen hastalıktan dolayı tükendiğgi düşünülmektedir. Ölüm tarihi belli değildir. Şairin ölümüyle ilgili ilk bilgi, 1922'de Türkmeneli 
dergisinde Allahgulu Garahanov tarafından verilmiştir. Şairin 50-60 yıl önce ( bu malumatın verildiği yıldan, yani 1922'den 50-60 yıl önce) vefat ettiği bildiriliyor (Karahanov 1922: 39). Şairi araştıranlardan biri olan Gurgenli Ahundov, Molla Nefes'in 1810'da doğmasına rağmen ölüm tarihi hakkında kesin bir bilgi bulunmadığını söylüyor (Ahundov 1939: 27; Gürgenli 1940: 6). Garrıyev, halk arasında söylenenlere dayanarak şairin $1810^{\prime}$ da doğduğunu ve 1860 'da öldüğünü belirtiyor (Qarrıyev 1947: 6). Shamiradov, şairin 1810'da Sarak'ta doğduğunu ve 1962'de Mari'de öldüğünü bildiriyor (Şamıradov 1955: 3). A. Aşırov ise şairin 1875 y1lında öldüğünü belirtmektedir (Aşırov 2010: 28). Şairin doğumu ve ölümü konusundaki tartışmalar bugün de devam etmektedir. Ancak, resmî edebî kaynaklarda bu y1llar 1810-1862. yıllar olarak belirtilmiştir. Konu ile ilgili çok farklı görüşler vardır. Bazı araştırmacılar, şairin 1860'lı yılların ortalarında, bazıları ise 1872'de vefat ettiği kanaatindedir. Şair, şiirlerinden birinde 60 yaşında olduğunu söylüyor:

Yaşın altmışa yetibdir, novca çağlardan geçip,

Şer işe baş qoyarsan, kari-rahmetden kaçıp.

Kahri-haktan korkubda, her günde göz yaşın seçip,

Her seherler "hu" deyib, vahdet şarabından içip.

Meşribu Mansur gibi mestane olan vakitdir.

Şairin ölümüyle ilgili olarak, Çarlık Rusyası'nın 19. yüzyıl Türkistan'ı işgal etmesi konusunda da bilgi var. Silahlı Rus askerlerine karşı neredeyse hiç silah tedariki bulunmayan Türkmen, Özbek, Kırgız, Karakalpak ve Tacik vatanseverler kalıcı bir duruş sergileyemiyorlardı. Molla Nefes, şiirlerinden hareketle vatanının cesur çocuklarına ilham vermekle kalmamış, 50 yaşın üzerinde olmasına rağmen savaşlarda yer almıştır. Bu savaşlardan birinde, şiirleriyle Türkmen savaşçılarını, hanlarını ve soylularını yücelten savaşçıları öven ve savaşları kazanmaya teşvik eden şair ağır yaralanarak şehit olmuştur.

\section{Molla Nefes'in Lirizm Yaratıcılığı}

Molla Nefes'in şiirlerinde sevgi teması önemli bir yere sahiptir ki, bu şiirlerde onun şairane söyleme şekli kendini göstermektedir. Onun "Beri gel”, "Bir damla bilen", "Göz", "Ansa", "Ner gergin" isimli şiirleri bu anlamda okuyucunun ruh dünyasına kuvvetli bir etki bırakır. Şair, bazı şiirlerinde halkın bağımsızlığı, birlik ve beraberliği hususunda gayret etmek konusundan söz açmıştır. Döneminin tarihî şahsiyetlerinden olan Karaoğlan Han'a 20'ye yakın şiir yazmıştır ki, burada da dönemin siyasi olayları içinde bulunduğu savaşlarla ilgili konulardan bahsediliyor. Şair "Gelen çağlar" adlı şiirinde Qaraoğlan Han gibi mertlere canının kurban olduğunu vurguluyor (Aşırov 2010: 28).

"Firağından" şiirinde sevgilisinin aşkından yandığını, onun güle konmuş bülbül olduğunu ve sevgilisinden onu uzak tutmamak arzusunu ifade etmiştir. "Kiçkine" ("Azınlık") isimli şiirinde kendini sevgiden yakan siyah, keman kaşlı, inci dişli, gül ağızlı bir sevgili tasvir etmiştir. Şiirlerinde sadece Türkmen birliğinden değil, Türk-İslam birliğinden de bahseden şair, "Cahana geldi” şiirinde Harezm'den 80 bin askerin Türkmen ordusuna yardım etmek için geldiğini sevinçle ifade ediyor. Şiirlerinde, sınırsız Türk yurdunun, türk boylarının ismini gururla anan şair, sanki Türkistan coğrafyasını gözler önüne seriyor. "Ansa" şiirinde açgözlüğü keskin şekilde eleştiren şair ebediyen olmayan fani dünyaya inanmamayı tavsiye etmiştir. "Nezerin yalan gönlüm" şiirinde zamaneden, insanlardan şikâyetçi olan şair, "Vaktidir" şiirinde filozofça insanlara nasihatler veriyor, daima cesur olmalarını, gerçeğe dayanmalarını, basit, inanç temelli bir yaşam sürdürmelerini öneriyor. "Feda eyledi" isimli şiirinde peygamberin hayatından bazı epizotları kaleme almıştır. "Muhammed" şiirinde Hz. Muhammed'in bir cevher gibi dünyaya gelerek cihanı 1şıklandırdığını anlatmıştır (Demirci 2017: 325-329).

Aman Kekilov da M. Nefes hakkında dikkat çekici bilgiler vermiştir. Molla Nefes ölmeden önce, Mehmet Rahim'e üç kitap ve bir kaç el yazması vermiş ve ölümüne kadar kitabın açılmamasını 


\section{F.Ü. Sosyal Bilimler Dergisi 2020-30/1}

istemiştir. Daha sonra torunu Hocaş onların hepsini bir çuvalın içine koyarak gömmüştür”( Kekilov 1957: 21).

Şairin "Yetişsin”, “Serdarı", "Berkarar olsun”, “Kara oğlan”, "Gelen Karaoğlan”, "Geldi”, "Beyler", "Deyim" gibi şiirleri savaşçı ruhu ile ayrılır. Şairin derin sosyal politik içerikli şiirlerinden olan (az sayıda da olsa) "Nesr gibi gez", "Geldim", "Haber ver", "Ayrıldım", "Var iken", "Olar", "Vaktidir" isimli şiirlerinde dünyanın adaletsizliğinden, felekten şikâyet etmek için güçlü motivasyonları vardır. Şairin "Muhammed", "Feda yedi", "Gördüm", "Eden celil” gibi şiirleri lirikasının dini şiirler bölümüne bağlanabilir. Şairin 1940 yılında yayınlanan ilk şiir kitabı sadece 27 şiir içermektedir. Daha sonra, 1947 tarihli bir kitapta 75 şiir yayınlanmış ve 1955 'te yayınlanmış kitapta sadece 70 şiir basılmış,b1961-62-63-73. yılların yayınlarında Sovyet döneminden kalma edebî mirasının küçük bir bölümü yansıtılmıştır (Türkmen şeir antologiyası. 2011: 217-75). Hatta şiirlerinden bazıları Miskin Nefesin, Mahtumkulu, M. V. Kemine, Talibi, Molla Murad, Kâtibi ve başkalarının adınyla kaydedilmiştir. Ancak, edebî eleştiriyle ilgili konular zaman içinde çözülmüştür (Molla 2010: 33 ). Türkmen birliği, dinî şiirler ve şarkı sözleri gibi üç tema, Mahtumkulu ve Molla Nefes yaratıcılığında açıkça görülüyor. Mahtumkulu, tema ve tür bakımından daha geniş ve kapsamlı olmasına rağmen, Molla Nefes'te lirizm daha çok hakimdir. Her iki sanatçının da Azerbaycan'da bulunduğuna dair bilgiler vardır. Orta Asya ve Kafkasya'nın birçok şehirlerinde bulunmuş, âşıklarla buluşup düğün meclisleri teşkil eden şairin şiirlerinde, Çerçov, Serahs, Murkala, Murgub, Mahi-şahi cahan, Ürgenç, Semerkant, Buhara, Andican, Harezmi, Kandahar, Kabil, Herat, Astrabad, Hamedan, İsfahan, Horasan, Tahran, Kazvin, Şam, Bağdat, Mısır, Irak, Rum, Fireng gibi ülkelerin ismi anılıyor. Bazı coğrafi konumların bir kısmının adı şiirsel ihtiyaçlardan dolayı anılmıştır. Ancak şairin Azerbaycan'da olduğu da şüphe doğurmuyor.

Terviz diyarında olmuşam seyyad,

Hezirbaycan şehrin gezdim adbaad.

Azerbaycanlı araştırmacı Ali Şamil, bugün Azerbaycan'a Türkmenistan'da hala Hezirbaycan dendiğini söylüyor (Ondəlib 2011).

Yukarıdakı mısralar da dediklerimizin kanıtıdır.

Şairin aşk acısı çektiği de olmuştur. Tahsilini bitirdikten sonra vatanına dönen Tanrıverdi, Durduhal isimli bir kıza aşık olmuş, ancak hiçbir zaman ona kavuşamamıştır. İlk aşkını hayatı boyunca unutamayan şair, her zaman onu hatırlamış, şiirlerinde bile ismini anmıştır.

Nefes söyler yara belim bağlaram,

Gece-gündüz derya gibi çağlaram,

Ta ölünce Durduhal der ağlaram,

Gözlerimden akan iki çay indi.

Böylece, Durduhal, Merv'den Tanrıverdi olarak giden, döndüğünde mükemmel bir eğitim almış biri olarak geri dönen Molla Nefes'in ilham perisine dönüşmüştür.

Ne yazık ki, şairin edebî mirasının büyük çoğunluğuna henüz ulaşılmamıştır. Eski Sovyetler Birliği zamanında Türk halklarının entelektüellerine karşı baskılar, Türk tarihine ve kültürel mirasına indirilen darbeler birçok sanatçı gibi, Molla Nefes'in de Sovyet Bolşevik ideolojisine aykırı eserler toplamasına, okumasına ve yayınlanmasına izin vermemiştir.

Dinî ve didaktik içerikli şiirleri de aynı kaderi yaşamak zorunda kalmıştır. Andelip, Azadi, Mahdumkulu, Magrubu, Kemine, Talibi, Seyidi, Zelili ve Kâtibi gibi Türk edebiyatının büyük ustaları ile aynı çizgide durmakta olan, 19. yüzyıl Türkmen şiirinin tarihinde parlak bir yetenek sahibi olarak tanınan, çok renkli geraylı, koşma, muhammes, politik içerikli şiirleriyle, yarattığı destanları ile Türkmen halkının zevkini okşayan Molla Nefes'in yaratıcılığı genç nesilleri terbiye etmiş, onlara 
millî düşünce aşılamış, saf ve gözyaşı gibi temiz bir çeşmeyi hatırlatıyor. Ruhunu ve gıdasını halk edebiyatından - Türkmen folklorundan alan eserleri ince, sade, hazin ve samimi olmasının yanı sıra tamamen orijinal ve tazedir. Doğu şiirine benzer lirik kompozisyonları özellikle dikkat çekicidir. Örneğin:

Tağı peykanından bağrım delindi,

Razıyam öldürüb canım al indi.

Qara zülfün üzre yüz-yüz bölündü.

Şairin "Dilbara", "Nazenin", "Gözlerin", “Ayrıldım", “Ola ya olmaya”, "İsteyib güzel yarı", "Güzel”, "Kiçgine", "Tapılmaz", "Dilber", "Kız", "Dedim-dedi” ve diğer şiirleri bu anlamda ön plana çıkmaktadır. Araştırmalar sonucunda şairin, yüzden çok şiiri olduğu ortaya çıkıyor ki, bunların da üçte biri şairi tanıyan insanlardan toplanmıştır. "Divan"1 olduğuna dair hiç bir bilgi yoktur (Aşırov 2010:28). Azerbaycan'da Molla Nefes'le ilgili boşluğu azıcık da olsa dolduran Ramiz Asker'in "Bu mekâna gelmişem" kitabı yayınlanmıştı. Kitapta Molla Nefes'in hayatı ve şiirleri hakkında dolgun bilgiler yer almaktadir.

Molla Nefes'le büyük selefi Mahdumkulu'nun yaratıcılığını karşılaştırırken, ilginç gerçekleri ortaya çıkıyor. Her iki şairin hayatı arasında 70 yıllık bir fark olmasına rağmen, bazı benzerlikler vardır. Bu benzerliği aynı manevi ortamda (ilk önce Buhara ve Hive'de eğitim almışlar), aynı programda yetişen her iki sanatçının yaratıcılıklarında görmek mümkündür.

\section{Molla Nefes'in şiirleri ile ilgili yapılan çalışmalar}

Şairin şiirleri ilk önce "Ruzname-i Mavera-i Bahr-i Hazar" gazetesinde yayınlanmıştır. Şiirler "Yay indi", "Hiç görmedim yıllarla", "Ovadan çık" ve "Bulunmaz" isimli şiirleri qazetenin 196, 202, 205, 214, 217, 230 numaralı yayınlarında yer almıştır. 1922'de Taşkent'te yayınlanan Türkmen Eli dergisinin 3. sayısında "Gönlüm", "Aklıma düştü", "Ansa" isimli şiirleri dünya görmüştür. Şairin şiirleri ilk kez 1940 yılında Gürgenli Ahundov tarafından yayınlanmıştır. Bu kitap 27 şiir içermektedir. Baymahammad Garrıyev tarafından yayınlanan bir sonraki bask1 - 1947'de 75 şiirden ve B. Shamiradov ve O. Yazimov tarafından yayımlanan kitap ise 70 şiirden ibarettir. 1961, 62, 63, 73'te Ashirov, Karriyev ve Kakilov tarafindan yayınlanan, 25'i yeni olmakla 98 şiirin bulunduğu büyük hacimli bir yayın olmuştur (Kekilov 1957: 10-11). Bu yayında "Aşkından", "Yara etsem", "Ziba Camal" ve "Çıkar" isimli şiirler, Türkmenistan Bilimler Akademisinin 71. klasöründe saklanan şiirlerdir ki, bunlar da o zamanlar adı bilinmeyen 19. yüzyıl şairi Miskin Nefes'indir. 1947'de yayınlanan şiirlerin Puraki'ye ait olup olmaması ile ilgili Geldiyev, Babayev, Tanriverdiyev, Avazgeldiyev gibi araştırmacıların farklı görüşleri vardır (Aşırov 2010:11). Ashirov, 1947. yıl baskısında yer almış "Gönlüm” isimli şiirin $\mathrm{H}$. Berkeliyev'e atıfta bulunarak M. Nefes'e ait olmadığını belirtiyor (Aşırov 2010:35). A. Gürgenli'ye göre, "Baba Rövşen" ve "İmam Hüseyin" isimli destanların şiirleri de M. Nefes'e aittir. Sadece bu bilgiler belirtilmediği için Andelip'e de ait sanılıyor. Türkmen edebiyatında aynı adı ve içeriği taşıyan farklı şairler bulunuyor (Ahundov 1939: $35)$.

Ayrıca M. Nefes'in Mahtumkulu, Kemine, Talibi ile de ortak şiirleri mevcuttur. "Yör bileni" şiirinin Mahtumkulu ile birlikte yazıldığı söyleniyor. Bununla birlikte, Aşırov bu şiirin daha çok M. Feraki'ye aid olduğunu düşünüyor. Bu yüzden Molla Nefes'le ilgili yayınlarda bu şiiri kabul etmemiştir (Aşırov 2010: 15). Bazen şairin şiirlerinden bazıları Oveztağan Kâtibi'nin adına bile kaydedilmiştir. "Kız" isimli şiiri Ş. Kandimov 1997 yılında Kâtibi'nin şiirleri içerisinde takdim etmiştir. Ancak kitabın ön sözünde, bu şiirin aslında $M$. Nefes'e aid olduğu vurgulanmıştır. Gandimov "Ağırlıkla uyuşmuyor", "Gelecek beş gün” ("Bu canı"), "Agzalalık ağır ile yaraşmaz", ve "Bu canı gördüm" isimli şiirleri M. Nefes'le Kâtibi'nin ortak şiirleri olarak görüyor (Qandımov 1997). Araştırmacı "Nazar kılsa dişlerine ve sevdiyim" ("Güzelim") isimli şiiri de bu listeye dahil ediyor (Aşırov 2010: 15). Nuralyev, Samoyloviç'in topladığı 15 şiirden "Ağzalalıq ağır ile 


\section{F.Ü. Sosyal Bilimler Dergisi 2020-30/1}

yaraşmaz", "Bu gün gelen dövranı”, "Bu canı gördüm”, "Dişlerine” şiirlerinin Molla Nefes’e ait ait olduğunu söylüyor (Nuralıyev 1971: 61). Bu şiirlerden "Bu gün gelen dövranı" şiiri hiçbir zaman Molla Nefes'e ait olarak yayınlanmamıştır. Gandimov, bunun Kâtibi'ye ait olduğunu belirtmiştir. Karrıyev ise gâh Kâtibi'ye ait kabul etmiş, gâh etmemiştir. Molla Nefes'le Talibi'nin bazı şiirlerinde benzerlik olduğunu görüyoruz. Molla Nefes'in "Bulunmaz" isimli şiiri 3 şaire ait kabul ediliyor: Molla Nefes, Talibi ve Molla Murat. Bununla birlikte, Molla Murad'ın kendi eli ile yazdığ El Yazmaları Enstitüsü'nün farklı elyazmalarında 376, 1164, 2121 numaralı klasörlerde bu şiir Molla Nefes'e ait olarak kabul edilmiştir. Enstitü'deki altı el yazmadan birinde şiir Molla Murada, ikisinde Talibiye, üçünde Molla Nefes'e ait olduğu söylenmiştir. En önemlisi ise şiir, Molla Nefes'in yazı stiline çok uygun gelmektedir (Aşırov 2010: 25-27).

Molla Nefes'in "Badem kabakları" isimli şiirin de aynı zamanda Talibi'ye ait ait olduğu ifade edilmiştir. Şiirin üç kopyasından ikisi Molla Nefes'in, biri ise Talibinin yazı stiline yakın olduğundan Molla Nefes'le ilgili kitaba dahil edilmesi uygun görülmemiştir (Aşırov 2010:28). Kemine'ye ait olduğu düşünülen "Midar sana" şiiri henüz Molla Nefes'e ait kabul edilerek yayınlanmamıştır. Şiir, 376-1010 numaralı elyazmalarda Molla Nefes'in, 844 ve 3 numaralı dosyalarda ise Keminenin adına tescil edilmiştir. Bunlardan, 3 numaralı klasördeki şiir birbirleriyle neredeyse aynı olan diğer klasörlerden farklıdır. Aşırov bu şiiri Kemine'ye ait olarak görüyor (Aşırov 2010:28).

\section{Molla Nefes'in "Bu mekâna gelmişem" poemi}

Şairin büyük ölçekli aşk şiirleri, içerik ve biçim bakımından farklılık gösteriyor. $\mathrm{Bu}$ bakımdan şairin "Ben bu mekâna gelmişem" isimli poemi eşsiz bir şaheserdir. Sevginin en yüksek şiirsel seviyesine- ulvileştirilmesine, hatta diyebiliriz ki, ilahileştirilmesine, Molla Nefes'ten başka kimsenin yaratıcılığında rastlanmamıştır. Şairin lirik yaratıcıllğının zirvesini oluşturan bu poemin her biri 6 mısra içeren 34 bentten oluşmaktadır. Müseddes türünde yazılan poem "aaaaba, ccccba, ssssta" şeklinde kafiyelenmiştir. Sevginin, aşkın marşı olarak kabul edilen poemin özelliklerine bakalım:

Poemde dikkat edilmesi gereken ilk şey, dinî imgelerin çoğunluk teşkil etmesidir. Bunların arasında Tanrı (diğer isimlerde de verilmiştir - Mevlam, Rahman, Murtaza pirim), melekler (Cebrail ve Azrail), peygamberler (İlyas, Davut, Lokman, Yusuf, Süleyman, Eyyup, İbrahim, Yakup, Hıdır, Sahip ahir ez Zaman, Mehdi ) ve isimleriyle olmasa da ferişteleri görüyoruz;

İkinci önemli nokta, bazı karakterlerin islam dinine mensup tarihî şahsiyetler olmasıdır ki, burada Amin ismi ile gördüğümüz Hz. Muhammed ve onun dinine ait dört tarihî sahabesinden Ömer, Ali, Osman ve Veysel Karani ile birlikte mutasavvıf şair Hoca Ahmed Yesevi'yi görüyoruz;

Üçüncüsü, poemde birçok efsanevi, mitik, ve tarihî şahsiyetle birlikte Süleyman'ın hanımı Belkıs'1, Yusuf'u seven Züleyha'yı, Mecnun, Ferhat, Harun, Hatem-i Tai ve İslam dinine büyük hizmetleri olan 360 yiğidin ismi anılıyor. Oldukça basit bir komploya sahip olan poemin merkezinde peygamberin ve meleklerin güzelliğine vurulduğu, âşı olduğu sevgilisi durmaktadır. Dünyadaki, kargaşayı gören Allah, bu karmaşaya sebep olanın canını almak için Azrail'i yeryüzüne gönderiyor. Ancak, kızı görünce "Ölmeye geldim” deyip Allah'ın emrini unutuyor. Ali'nin Zülfikar'ını yere düşürmesi, dertlerin dermanı olan Lokman'ın kıza derdine derman olması için yalvarması, bu kızı görürken Yusuf'un Züleyha'yı, Süleyman'ın Belkıs'ı unutmasının sebebi de kızın güzelliğinden dolayı fenalaşmıs olmasıdır. Sükûnet olmadığını görünce Allah, Cebrail'i yeryüzüne gönderir, yine bir sonuç vermez. $\mathrm{O}$ da âşıkların saflarına katılır. Kızın güzelliği onu hayrete düşürür.

« Cebrail nazar salar, qafil oturmuş Osman,

Bihuş, yerde terpener Xıdır, İlyas, Süleyman.

Yusuf, Eyyub, erenler, Yakup, Davud, hem Loğman,

Veys, Ahmet Yasevi, İbrahim çekip arman, 
İsa özün unudub,

Bir dilberi yad edib,

Derler: «Eşq yandırdı, hakk, lerzana gelmişem”.

Yeryüzündeki vaziyetten haberdar olmak için lamekandan yer yüzüne inen Allah bile kızı görünce kendinden geçiyor. Bu an kız Molla Nefes'in sevgilisi olduğunu söylüyor. Poemin sonunda şair şöyle diyor:

Çekdi sünbül saçların nazlı dilber yüzünden,

Gün tutulub, bu alem şöle aldı gözünden,

Mövlam taqet getirmez, getdi şol dem özünden,

Dedi yarım: «Hakk aşik döne bilmez sözünden,

Hökmü revan Birivar,

Ben Nefese xiridar,

Bir şol deyib ezelden, bu mekana gelmişem.

Çıxdı suyi-asmana geceler çıkan ahım,

Aşna oldu canana, nazar kılsın xudahım,

Vallah, hakkın alnında olmaz benim günahım,

Maşuk varın saklıyor, eşq mukaddes penahım,

İnsan Nefesin yarı,

Külli alem kararı,

Ben Endelip hoşbaht, nov reyhana gelmişem.

\section{Değerlendirme ve Sonuç}

Bu makalede XIX. asır Türkmen edebiyatının önemli isimlerinden olan Molla Nefes'in hayatı ve yaratıcıllı̆̆ , şiirleri, poemi tetkik olunmuştur. Çalışma sonunda şu kanaate gelinmiştir ki, Molla Nefes aynı zamanda Nurmuhammed Andelip edebî mektebinin temsilcisidir. Andelip'ten etkilenen şairin yaratıcılığında, lirikanın bilhassa yer tuttuğunu görmüş oluyoruz. Şiirlerinde halkınının, milletinin derdine ortak olmuş, vatanseverliği temsil etmiştir. Bununla kalmamış Türkmenistan'ın ağır günlerinde vatan oğullarına yazdığı şiirlerle ruh vermiş, hatta savaşlara bile katılmıştır. Beyit, bent, dörtlük, beşlik nazım birimlerini kullanan şairin aşk ve sevgiyle ilgili şiirlerinde lirizm ve coşkunluk hâkimdir. Ancak zaman-zaman şairin didaktik özellikler gösteren şiirlerine de rastlanmaktadır. Makalede şairle ilgili yapılan çalışmalar hakkında da bilgi verilmiştir. Ülkemizde şairin şiirlerini Ramiz Asker Azerbaycan Türkçesine çevirmiştir. "Bu mekâna gelmişem" isimli kitabında şairin şiirlerini toplamıştır. Şairin 119 şiiri olduğu malumdur. Farklı Türk lehçeleri konuşan ülkelerde de büyük şairle ilgili bir takım çalışmalar yapılmıştır. Lakin, şairin değerini ortaya koyacak kadar akademik çalışmaların yapılmadığı görülmektedir.

\section{KAYNAKLAR}

Aşırov A. Molla Nepes. Aşqabat, 2010, TDN, s.28 


\section{F.Ü. Sosyal Bilimler Dergisi 2020-30/1}

Demirci Metin. Büyük Türkmen şairi Molla Nefes // Uluslararası türkçe edebiyyat Kültür Dergisi, Say1 6, 2017, Türkiye, s.312-330

Ondəlib N. Şeirlər, poemalar, dastanlar. Tərtib edən, türkməncədən uyğunlaşdıran və ön sözün müəllifi Prof. Dr.Ramiz Oskər. Bak1: MBM, 2011, 292 s.

Gürgenli A. Molla Nepes. Lirika (Saylayan qoşqular-Seçilmiş şeirler) Aşgabat, 1940, Türkmen Dövlet neşriyyat1, s.6

Gürgenli Ahundov. Türkmen klassik şahiri- Molla Nepes ve onun dörüdiciliği (Türkmen klassik şairi-Molla Nepes ve onun yaradıcılı̆̆ı) // Sovet edebiyyatı jurnalı, №5, 1939, s.27

Karahanov A. Türkmen Şahyrlary // Türkmen eli dergisi, №3, 1922, s.39

Kaya D. Diydim diydı" şeir söyleme geleneyi bağlamında Molla Nefes'in şiirleri / Molla Nefes ve XIX esr Türkmen edebiyyatı simpoziumu. 7-10 nisan, 2010, s.6

Kekilov A. Molla Nepes. Aşgabat, 1957,TDN, s.21

Qandımov Ş., Kâtibi. Goşgular. Aşgabat,1997, TMGí

Qarrıyev B.Molla Nepes. Lirika. Aşqabat, 1947,Türkmen Devlet Neşriyatı, s.6

Molla Nefes. Bu mekana gelmişem. Türkmenceden uyğunlaştıran ve ön sözün müellifi Ramiz Esker. Bak1, MBM, 2010, 196 seh.

Molla Nefes. Seçilmiş eserleri. Hazırlayan R.Esker. Bakı: MBM, 2010, s.4

Nuralıyev D. Akademik A.N. Samoyloviç Türkmen edebiyyatı haqqında. Aşqabat: Elm neşriyyatı. 1971, s.61

Şamıradov B., Yazımov O. Molla Nepes. Lirika, Aşqabat, 1955, TD Neşriyatı, s.3

Türkmen şeir antologiyası. XVII-XIX esrler. Türkmenceden dilimize uyğunlaştıran prof. Dr. Ramiz Esker, Bak1-2011, 400 seh

http: //www yagmurdergisi.com.tr / konu / 19-asır-turkmen şairi-mollanepes 